Supporting information for:

\title{
Negatively Charged Lipid Membranes Catalyze Supramolecular Hydrogel Formation
}

Frank Versluis, ${ }^{a}$ Daphne M. van Elsland, ${ }^{b}$ Serhii Mytnyk, ${ }^{a}$ Dayinta L. Perrier, ${ }^{a}$ Fanny Trausel, ${ }^{a}$ Jos M. Poolman, ${ }^{a}$ Chandan Maity, ${ }^{a}$ Vincent A. A. le Sage, ${ }^{a}$ Sander I. van Kasteren, ${ }^{b}$ Jan H. van Esch $^{a}$ and Rienk Eelkema*a

\footnotetext{
${ }^{a}$ Department of Chemical Engineering, Delft University of Technology, van der Maasweg 9, $2629 \mathrm{HZ}$ Delft, the Netherlands

${ }^{\text {b }}$ Leiden Institute of Chemistry, Leiden University, P.O. box 9502, 2300 RA, Leiden, The Netherlands
}

\section{Table of contents}

\section{Materials}

\section{Experimental section}

$\begin{array}{lr}\text { Figure S1: Lipid structures } & 6\end{array}$

Figure S2: Liposome sizes $\quad 6$

$\begin{array}{ll}\text { Table S1: Average hydrodynamic diameters of the liposomes } & \mathbf{7}\end{array}$

Table S2: Zeta-potentials of the liposomes $\quad 7$

Figure S3: Influence of liposomes on rate of hydrazone formation $\quad \mathbf{8}$

Figure S4: Influence of DPPG on the elastic modulus of the hydrazone based gel 9

Figure S5: Influence of DPPG concentration on gel network morphology 9

Figure S6: Fiber morphology studied through Cryo-TEM 10

$\begin{array}{ll}\text { Figure S7: Fiber-bilayer interactions studied through microcalorimetry } & 10\end{array}$

Figure S8: Gel fibers located at the bottom of the microscopy slide 11

Figure S9: Interactions between DOPG giant vesicles and probe $\mathbf{4}$

Figure S10: Content release of DPPG and DOPG liposomes upon the addition of 2

Figure S11: Size and zetapotential of DOPG liposomes + 2

Figure S12: Showing gelation at fixed HeLa cells $\quad 13$

Figure S13: Co-localization of probe 4 and living HeLa cells 13

Table S3: Cell viabilities upon the addition of components 1 and 2

$\begin{array}{ll}\text { References } & 14\end{array}$ 


\section{Materials}

All lipids, sulforhodamine B and Sephadex G-50 were purchased from Sigma Aldrich. Lipid probe $\mathbf{5}$ was purchased from AvantiLipids. Precursors $\mathbf{1}$ and $\mathbf{2}$ and aldehyde bearing probe $\mathbf{4}$ were synthesized as described in our earlier work. ${ }^{1}$ Compound 6 was synthesized as previously reported. ${ }^{2}$

\section{Experimental section}

\section{Liposome formation}

Small unilamellar vesicles

To form small unilamellar liposomes, $10 \mathrm{mM}$ stock solutions of the lipids were prepared in $\mathrm{CHCl}_{3} / \mathrm{MeOH}(2: 1 \mathrm{v} / \mathrm{v})$. The appropriate volume of stock solutions were pipetted in glass vials and evaporated using a rotary evaporator. For confocal samples, $0.5 \mu \mathrm{M}$ of 5 was added to the lipid mixture prior to the evaporation of the organic solvent. Subsequently, the appropriate amount of buffer solution was added to the lipid film and sonicated for $5 \mathrm{~min}$. at $55^{\circ} \mathrm{C}$.

\section{Sulforhodamine B loaded small unilamellar vesicles}

Lipid films were prepared as described before. Phosphate buffer (100 mM, pH 7.0) containing 20 mM sulforhodamine B was added to the lipid film, yielding a concentration of $5 \mathrm{mM}$ lipid. Next, the sample was sonicated for $5 \mathrm{~min}$. at $55^{\circ} \mathrm{C}$. To remove the sulforhodamine not encapsulated in the liposomes, purification using a column composed of Sefadex G-50 beads was performed. The loaded liposomes were harvested and immediately used.

\section{Giant vesicles}

The formation of giant vesicles was performed using the slow hydration method. ${ }^{3}$ Lipid films were formed as previously described. A $10 \mathrm{mM}$ phosphate buffer was added to the lipid film, yielding a final lipid concentration of $0.2 \mathrm{mM}$. Samples were left overnight at $50^{\circ} \mathrm{C}$ and the giant vesicles were harvested by pipetting with a tip that was cut around $1 \mathrm{~cm}$ from the top.

\section{Size distribution and zeta potential of small unilamellar liposomes}

To determine the size distribution and zeta potential of the small unilamellar liposomes, we employed a Malvern Nano ZS 3600 zetasizer. Lipid concentrations were $1 \mathrm{mM}$ for size measurements and $0.1 \mathrm{mM}$ for zeta potential measurements, in a $100 \mathrm{mM}$ phosphate buffer of $\mathrm{pH}$ 7.0. The laser wavelength was $633 \mathrm{~nm}$ and the scattering angle was $173^{\circ}$. For size measurements, the intensity 
distribution is depicted in the graphs. For individual liposome batches the sample was allowed to equilibrate for 2 minutes. Measurements were performed at $25^{\circ} \mathrm{C}$.

\section{Minimum gelation concentration (MGC)}

Stock solutions of $1(40 \mathrm{mM})$ and $2(240 \mathrm{mM})$ were mixed with liposomal dispersion $(40 \mathrm{mM})$ in appropriate amounts in a sample vial of $1 \mathrm{~mL}$ (sample size: $0.5 \mathrm{~mL}$ ) and left to react overnight. Evaluation of gelation was performed by turning the vials upside down. If the entire sample remained at the top of the vial, this was reported as a gelled sample. All experiments were performed in a 100 $\mathrm{mM}$ phosphate buffer of $\mathrm{pH}$ 7.0.

\section{Cryo-TEM}

A few microliters of a suspension containing $5 \mathrm{mM}$ DPPG liposomes, $1 \mathrm{mM} 1$ and $6 \mathrm{mM}$ 2, were deposited on a Quantifoil R 1.2/1.3 Holey Carbon coated grid. After blotting, the grid was rapidly frozen in liquid ethane (Leica EM GP) and stored in liquid nitrogen until observed. Grids were observed in a Gatan model 626 cryo-stage in a JEOL JEM1400 Plus electron microscope, operating at 120 kV. Micrographs were recorded under low dose conditions on a slow scan CCD camera (Gatan, 830).

\section{Microcalorimetry}

Phase transition temperatures of DPPG liposomes were determined using ultrasensitive Differential Scanning Calorimetry (VP-DSC, MicroCal). The sample (either $10 \mathrm{mM}$ DPPG or $10 \mathrm{mM}$ DPPG with 2 $\mathrm{mM} 1$ and $12 \mathrm{mM}$ 2) was loaded in the cell, while the reference cell contained buffer. The gel experiment was incubated overnight in the cell. All experiments were conducted in a $100 \mathrm{mM}$ phosphate buffer of $\mathrm{pH} 7.0$. Four scans (heating and cooling) were performed, with a rate of $1{ }^{\circ} \mathrm{C}$ $/ \mathrm{min}$, from $20^{\circ} \mathrm{C}$ to $80^{\circ} \mathrm{C}$.

\section{Rheology}

Oscillatory experiments were performed using a rheometer (AR G2, TA instruments) in a straincontrolled mode, equipped with a steel plate and plate geometry of $40 \mathrm{~mm}$ in diameter, equipped with a water trap. The temperature of the plates was controlled at $25^{\circ} \mathrm{C}$. All solutions were prepared from aqueous $100 \mathrm{mM}$ sodium phosphate buffer at pH 7.0. A sample vial (glass, $4 \mathrm{ml}$ ) was filled with the appropriate amounts of stock solutions of 1, 2 and liposomes, yielding total concentrations of 20 $\mathrm{mM} 1$ and $120 \mathrm{mM}$ 2. Immediately after mixing, the vial was shaken vigorously and the $1 \mathrm{~mL}$ content was poured onto the rheometer plate.

\section{Confocal microscopy}


Confocal laser scanning micrographs were obtained with a Zeiss LSM 710 confocal laser scanning microscope equipped with a Zeiss Axio Observer inverted microscope and a 40x Plan Fluor oil immersion objective lens (NA 1.3) using an incident laser. The confocal pinhole was set to 1.0 airy unit and the data files were processed using ZEN 2011 software. Samples were prepared in a $\mu$-Slide 8 well (Ibidi) microscopy slide with a glass bottom. Probe 4 was excited at $488 \mathrm{~nm}$ and probe 5 was excited at $534 \mathrm{~nm}$.

Influence of DPPG on gel network morphology

Appropriate amounts of 1, 2, 4 and DPPG dispersions in $100 \mathrm{mM}$ phosphate buffer ( $\mathrm{pH}$ 7.0) were mixed to yield concentrations of $3 \mathrm{mM}, 18 \mathrm{mM}$ and $30 \mu \mathrm{M}$, respectively. Samples were left to react overnight at room temperature in the microscopy chamber and were imaged the next day.

\section{Imaging of giant vesicles and gelation}

Giant vesicles were mixed with appropriate amounts of 1, 2, 4 in $10 \mathrm{mM}$ phosphate buffer (pH 7.0) were mixed to yield concentrations of $2 \mathrm{mM}, 12 \mathrm{mM}$ and $30 \mu \mathrm{M}$, respectively. Samples were left to react overnight at room temperature in the microscopy chamber and were imaged the next day.

\section{Experiments with fixed HeLa cells}

Appropriate amounts of 1, 2 and 4 in $100 \mathrm{mM}$ phosphate buffer $(\mathrm{pH} \mathrm{7.0)}$ were added to fixed HeLa cells to yield concentrations of $2 \mathrm{mM}, 12 \mathrm{mM}$ and $30 \mu \mathrm{M}$, respectively. Samples were left to react overnight at room temperature in the microscopy chamber and were imaged the next day.

\section{Experiments with living HeLa cells}

Appropriate amounts of 1, 2 and $\mathbf{4}$ in DMEM were added to living HeLa cells, yielding concentrations of $0.5 \mathrm{mM}, 3 \mathrm{mM}$ and $30 \mu \mathrm{M}$, respectively. Samples were left to react overnight at $37^{\circ} \mathrm{C}$ and $5 \% \mathrm{CO}_{2}$ in the microscopy chamber and were imaged the next day.

\section{$3 D$ reconstruction of $z$-stack showing gel fibers in the HeLa cells}

Z-stacks of the fibers (4) and nuclei (Hoechst) fluorescence within HeLa cells were obtained by taking confocal images images with a spacing of $1 \mu \mathrm{m}$. Subsequently, ImageJ was used to generate the 3D reconstruction. Figure $3 \mathrm{C}$ shows a single angle of this $3 \mathrm{D}$ reconstruction, the full image can be viewed from all angles in the supplementary video.

\section{Fluorescence measurements}

Content leakage of DOPG and DPPG small unilamellar vesicles upon the addition of 2 
Measurements were recorded on a Jasco J-815 CD spectrometer. The excitation wavelength was set at $560 \mathrm{~nm}$ and fluorescence emission was measured at $590 \mathrm{~nm}$. Sulforhodamine B loaded DPPG or DOPG vesicles (for preparation, see above) were mixed with 2, yielding final concentrations of \pm 1 $\mathrm{mM}$ of lipid and $48 \mathrm{mM} \mathrm{2}$. Measurements were started immediately after mixing and fluorescence intensity was monitored for $1 \mathrm{~h}$.

\section{UV-vis measurements}

UV-Vis spectroscopic measurements were performed on an Analytik Jena Specord 250 spectrophotometer. Quartz cuvettes of $1 \times 1 \mathrm{~cm}$ were placed inside a 6 -sample holder and measurements were performed every 60 seconds at $480 \mathrm{~nm}$, with a slit of $1 \mathrm{~nm}$. The relative reaction rates were determined by calculating the slope of each curve and normalizing these based on the control measurement that did not contain liposomes.

\section{Cell Culture}

Hela cells were cultured in Dulbecco's Modified Eagle Medium (DMEM), supplemented with $10 \%$ heat-inactivated fetal calf serum, $2 \mathrm{mM}$ L-glutamine, penicillin (100 I.U./mL) and streptomycin $(50 \mu \mathrm{g} / \mathrm{mL})$. Hela cells were seeded $\left(7 \times 10^{4}\right)$ on a 8 well chamber slide (Ibidi) with a glass bottom and left to grow overnight. Cells were fixed with $4 \%$ paraformaldehyde in PBS for 15 min. The unreacted paraformaldehyde was subsequently removed by washing with PBS (3x).

\section{Cell viability}

Cell viability was checked through a standard trypan blue assay. HeLa cells were incubated with

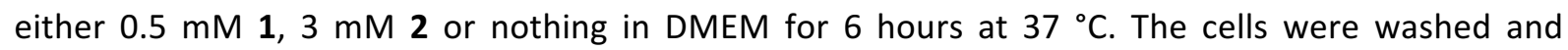
detached from the surface through the addition of trypsin for 5 minutes and the reaction was quenched by the addition of DMEM. Cells were collected upon centrifugation and resuspended in DMEM. Subsequently, trypan blue was added and the number of viable cells was determined using a TC20 bio-rad automated cell counter. 


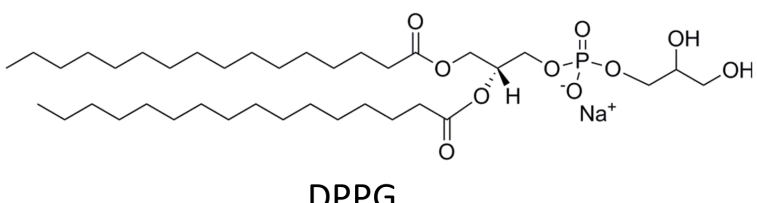

1,2-dipalmitoyl-sn-glycero-3-phospho-(1'-rac-glycerol)

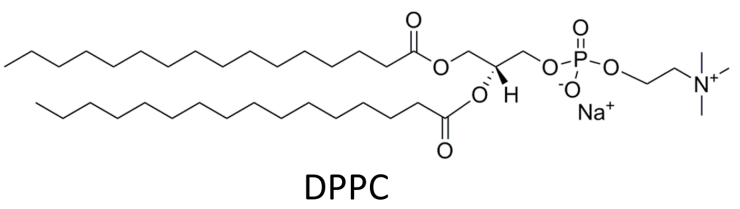

1,2-dipalmitoyl-sn-glycero-3-phosphocholine

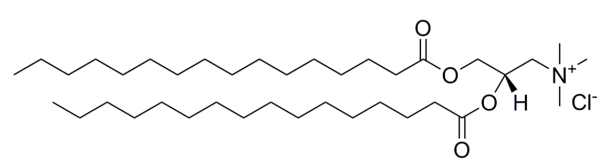

DPTAP

1,2-dipalmitoyl-3-trimethylammonium-propance

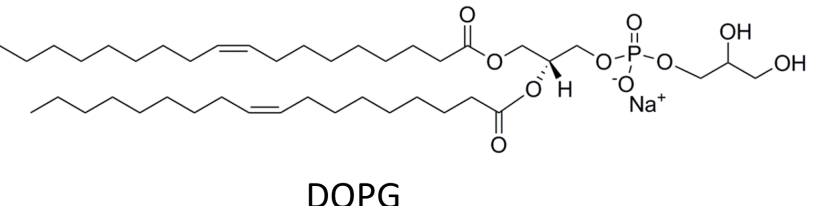

1,2-dioleoyl-sn-glycero-3-phospho-(1'-rac-glycerol)

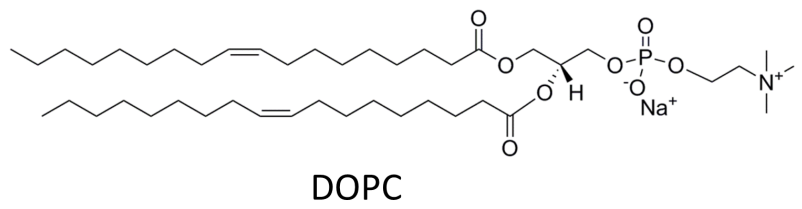

1,2-dioleoyl-sn-glycero-3-phosphocholine

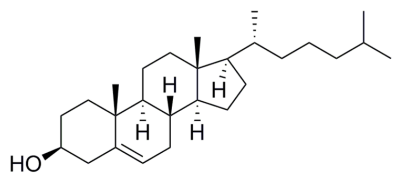

Cholesterol

Figure S1. Overview of the chemical structures of the lipids used in this study.

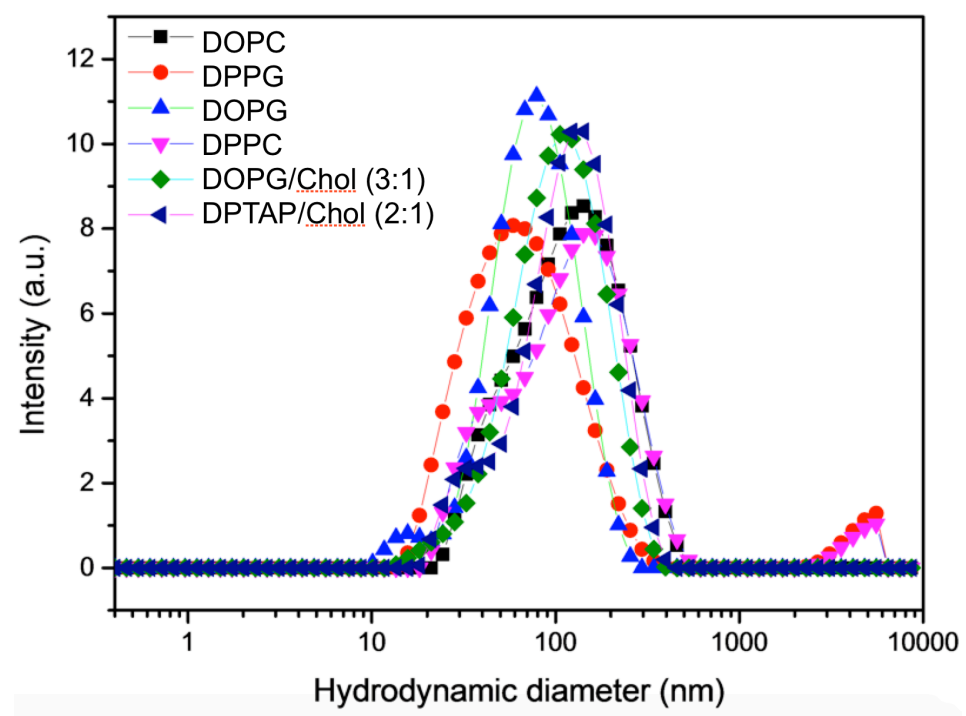

Figure S2. Size intensity distributions of all the used liposomes, determined using dynamic light scattering (DLS) in $1 \mathrm{mM}$ lipid samples, $100 \mathrm{mM}$ phosphate buffer at $\mathrm{pH} 7.0,25^{\circ} \mathrm{C}$. 
Table S1. Average hydrodynamic diameters of the liposomes used in this study.

\begin{tabular}{|l|l|}
\hline Liposome composition & Average hydrodynamic diameter $(\mathrm{nm})$ \\
\hline DPPG & 66 \\
\hline DOPG & 77 \\
\hline DOPC & 98 \\
\hline DPPC & 95 \\
\hline DOPG + Cholesterol (3:1) & 108 \\
\hline DPTAP + Cholesterol (2:1) & 88 \\
\hline
\end{tabular}

Table S2. Zeta potentials for all the liposomes used in this study. Lipid concentration was $1 \mathrm{mM}$ in $100 \mathrm{mM}$ phosphate buffer at $\mathrm{pH}, 25^{\circ} \mathrm{C}$.

\begin{tabular}{|l|l|}
\hline Liposome composition & Zeta potential $(\mathrm{mV})$ \\
\hline DPPG & -31 \\
\hline DOPG & -36 \\
\hline DOPC & -4.0 \\
\hline DPPC & -3.4 \\
\hline DOPG + Cholesterol (3:1) & -37 \\
\hline DPTAP + Cholesterol (2:1) & 28 \\
\hline
\end{tabular}


A)<smiles></smiles>

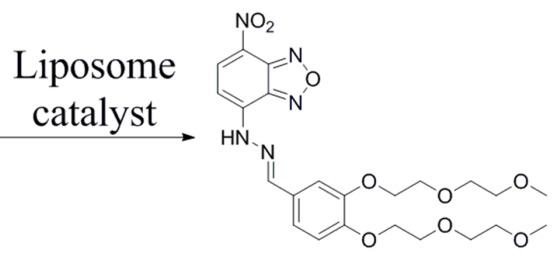

6

2

7

B)

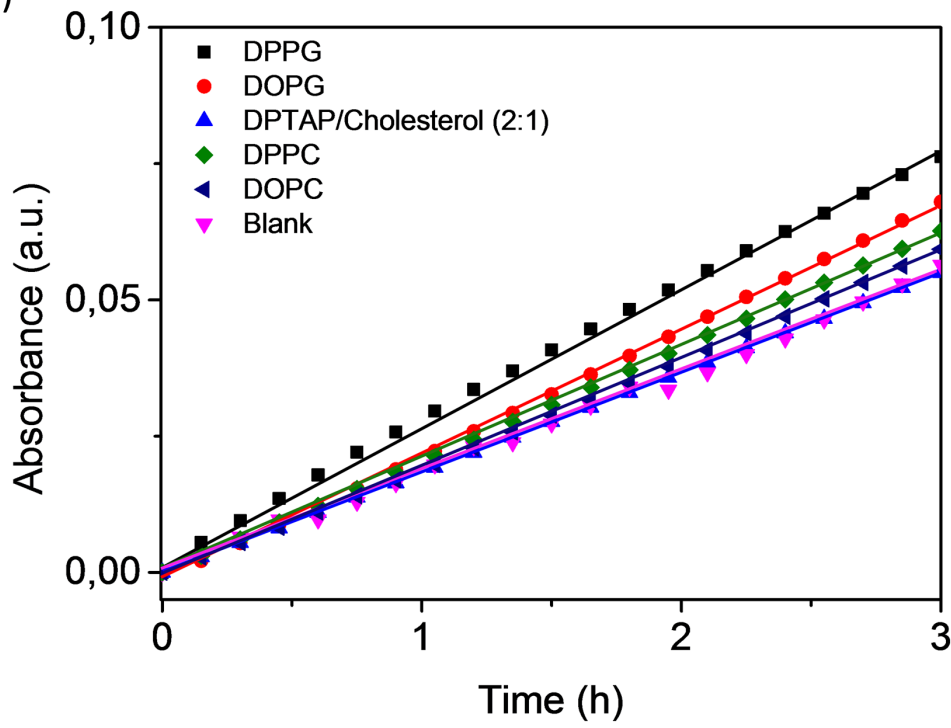

C)

\begin{tabular}{|l|l|}
\hline Lipid $(\mathbf{5} \mathrm{mM})$ & $\boldsymbol{k}_{\text {rel }}$ \\
\hline DPPG & 1.22 \\
\hline DOPG & 1.16 \\
\hline DOPC & 1.02 \\
\hline DPPC & 1.07 \\
\hline DPTAP & 0.94 \\
\hline Blank & 1 \\
\hline
\end{tabular}

Figure S3. Influence of liposomes on the formation kinetics of hydrazone product 7. A) Reaction scheme showing the aldehyde (2) and hydrazide (6) reactants and the hydrazone (7) product. B) Plot showing the absorbance of the hydrazone product over time, measured at $480 \mathrm{~nm}$, with a variety of liposomes and without liposomes (blank). C) Relative reaction rates as a function of lipid structure. Conditions: all samples contained $0.045 \mathrm{mM} 6$ and $2.5 \mathrm{mM} \mathrm{2}$, in a $100 \mathrm{mM}$ phosphate buffer at $\mathrm{pH}$ 7.0, measurements were performed at $25^{\circ} \mathrm{C}$. 


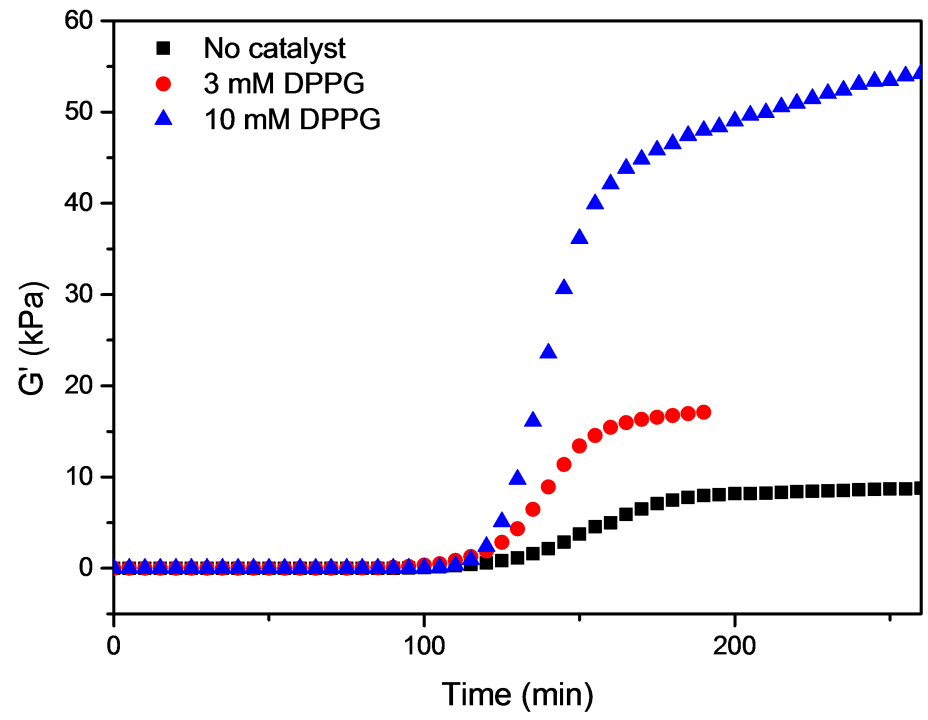

Figure S4. Influence of DPPG concentration on gel network stiffness $\left(G^{\prime}\right)$, as determined through rheology. Conditions: $20 \mathrm{mM} 1$ and $120 \mathrm{mM}$ 2, in $100 \mathrm{mM}$ phosphate buffer $\mathrm{pH} 7.0$, at $25^{\circ} \mathrm{C}$.
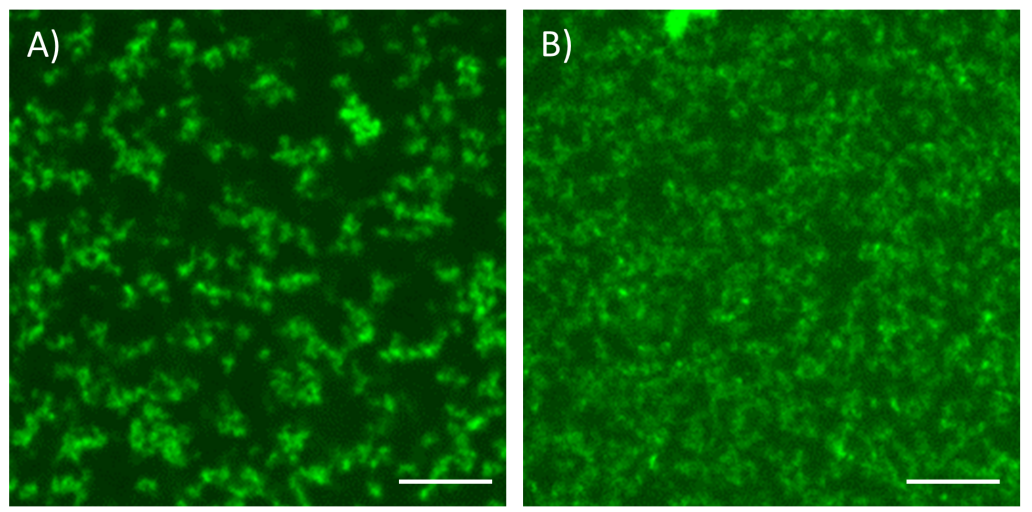

Figure S5. Influence of DPPG concentration on gel network morphology (enlargement of Figure $1 \mathrm{E}$ D). Both samples contain $3 \mathrm{mM} \mathrm{1,18} \mathrm{mM} \mathrm{2,} 30 \mu \mathrm{M} \mathrm{4}$, with A) $3 \mathrm{mM}$ DPPG and B) $10 \mathrm{mM}$ DPPG. 

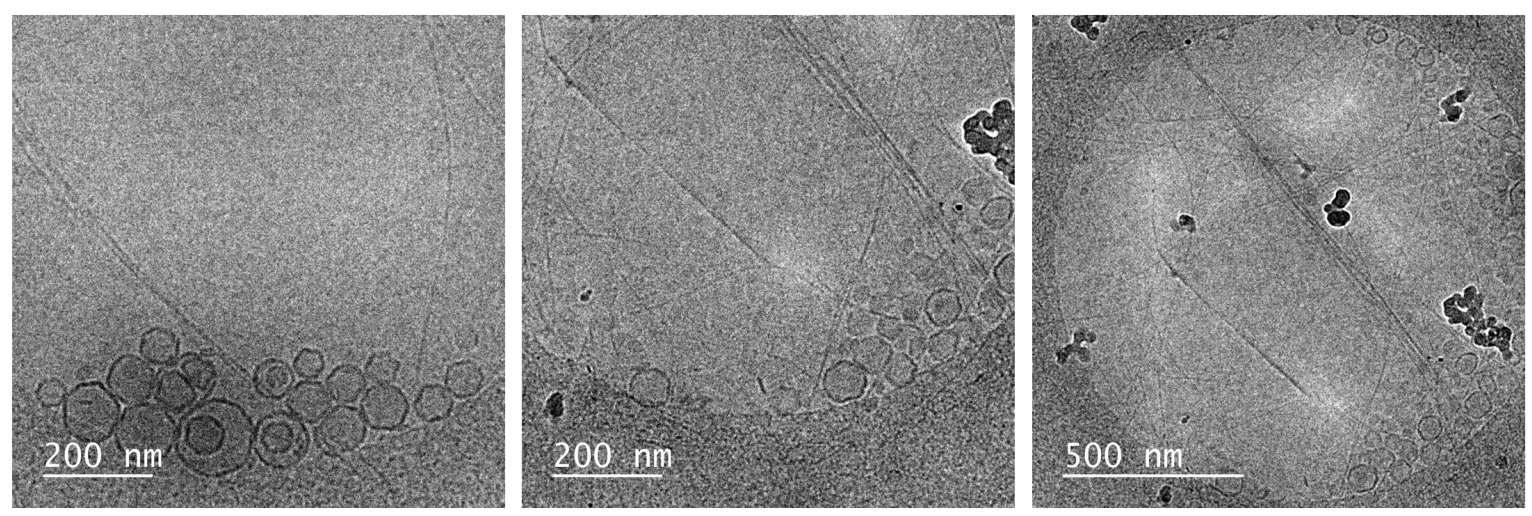

Figure S6. Cryo-TEM micrographs of a suspension of liposomes and gel components (5mM DPPG liposomes, $1 \mathrm{mM} 1$ and $6 \mathrm{mM} 2$ in a $100 \mathrm{mM} \mathrm{pH} 7.0$ phosphate buffer), incubated overnight at room temperature. Typical fiber diameter is $\sim 6 \mathrm{~nm}$.

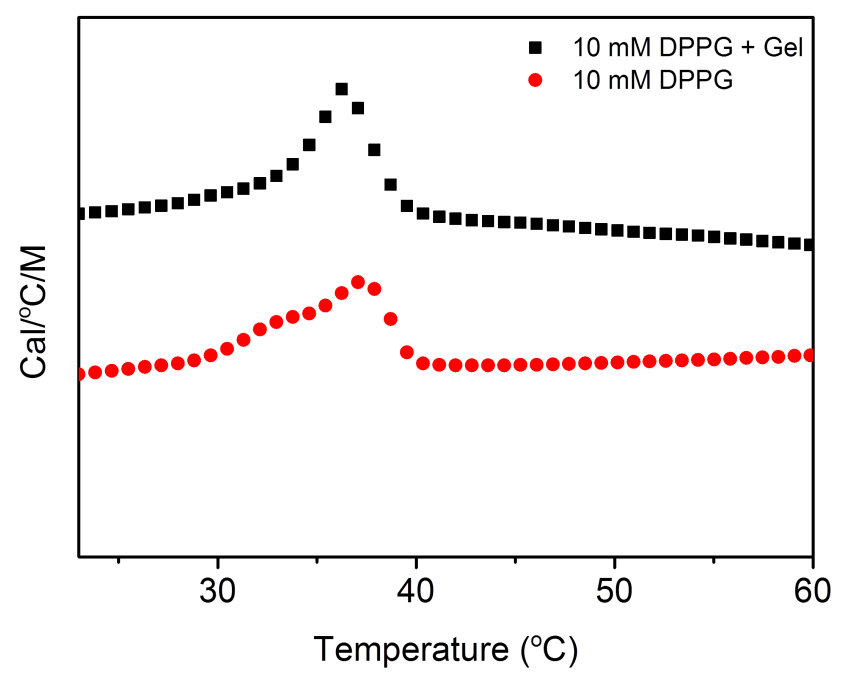

Figure S7. DSC traces of DPPG liposomes in pure buffer or in the presence of gel fibers. Conditions: $10 \mathrm{mM}$ DPPG in pure buffer or in buffer with $2 \mathrm{mM} 1$ and $12 \mathrm{mM} 2$ (overnight incubation).
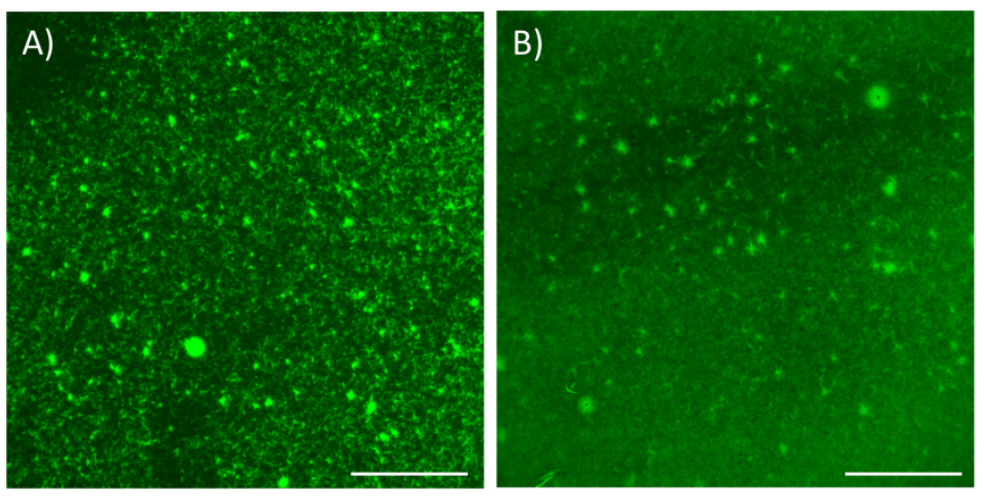

Figure S8. A-B) Gel fibers observed at the bottom of the well containing DPPG giant vesicles, precursors 1 and 2 and gel fiber probe 4. Concentrations: $0.2 \mathrm{mM}$ DPPG, $4 \mathrm{mM} \mathrm{1,24} \mathrm{mM} 2$ and 30 
$\mu \mathrm{M} 4$ in $100 \mathrm{mM}$ phosphate buffer of pH 7.0. Imaging took place after overnight incubation at room temperature. Scale bars: $50 \mu \mathrm{m}$.
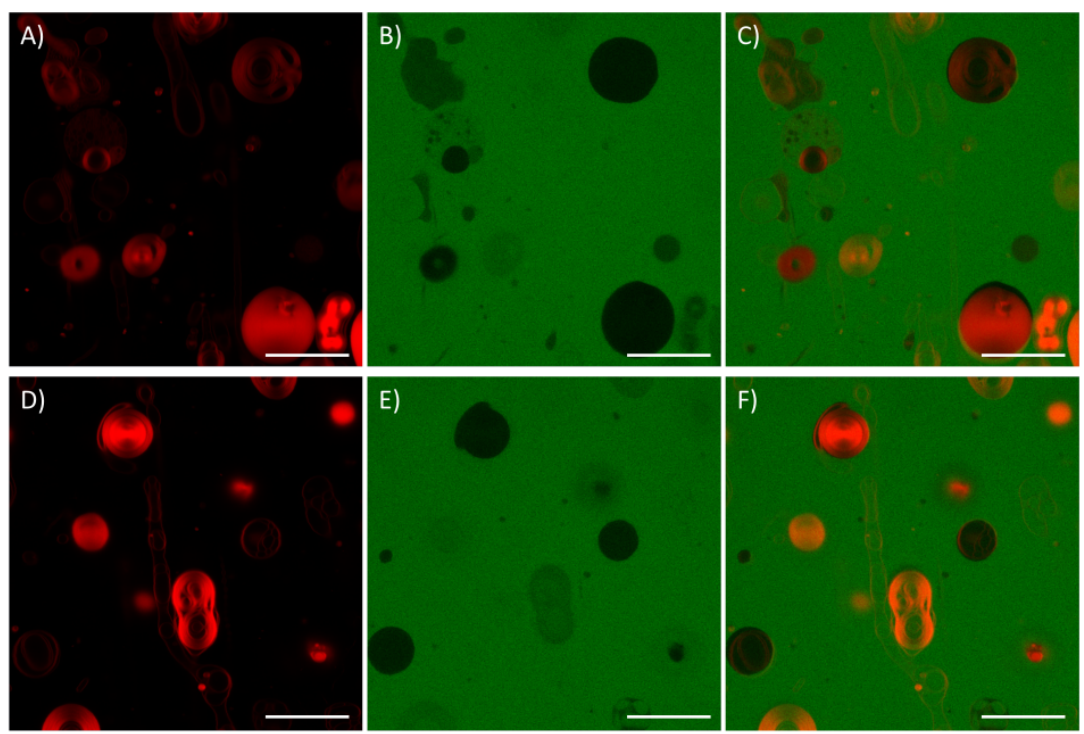

Figure S9. Confocal images revealing the lack of interaction between DOPG membranes and probe 4. $A, D)$ fluorescence of lipid probe $5, B, E)$ fluorescence of probe 4 and $C, F)$ overlay. Conditions: giant vesicles were formed using $0.2 \mathrm{mM}$ DOPG $+0.5 \mu \mathrm{M} 5$ and incubated overnight with $30 \mu \mathrm{M} 4$ in 10 $\mathrm{mM}$ phosphate buffer of $\mathrm{pH} 7.0$, at room temperature. Scale bars: $50 \mu \mathrm{m}$.

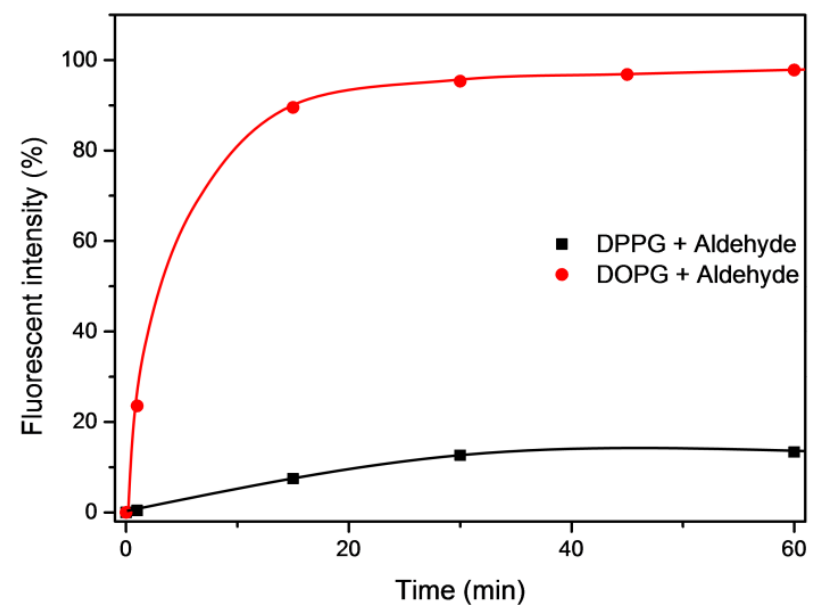

Figure S10. Release of sulforhodamine B by DPPG and DOPG liposomes upon the addition of the aldehyde precursor. Conditions: $1 \mathrm{mM}$ DOPG/DPPG liposomes, $48 \mathrm{mM} \mathrm{2,} \mathrm{in} 100 \mathrm{mM}$ phosphate buffer of $\mathrm{pH}$ 7.0, at room temperature. Fluorescence monitoring was started immediately after the addition of 2. 


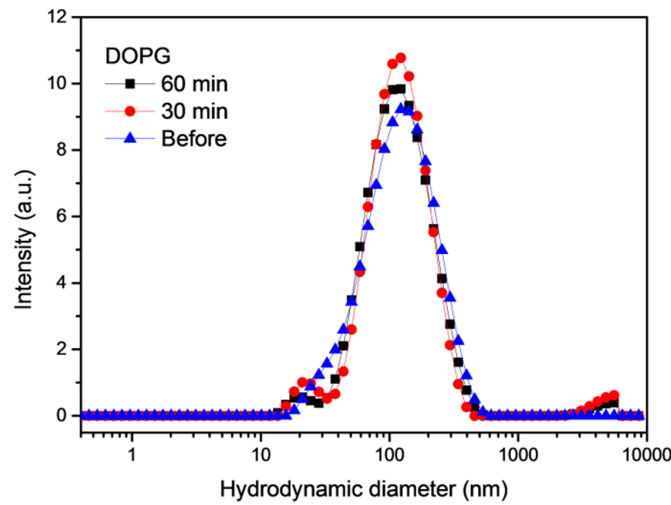

\begin{tabular}{|l|l|}
\hline Time after addition of $\mathbf{2}(\mathbf{m i n})$ & Zeta potential DOPG liposomes $(\mathbf{m V})$ \\
\hline 0 & -36 \\
\hline 30 & -38 \\
\hline 60 & -38 \\
\hline
\end{tabular}

Figure S11. Influence of precursor 2 on the size distribution and zeta potential of small DOPG liposomes. Conditions: $1 \mathrm{mM}$ DOPG lipid with $48 \mathrm{mM}$ 2, in $100 \mathrm{mM}$ phosphate buffer (pH 7.0) at room temperature.
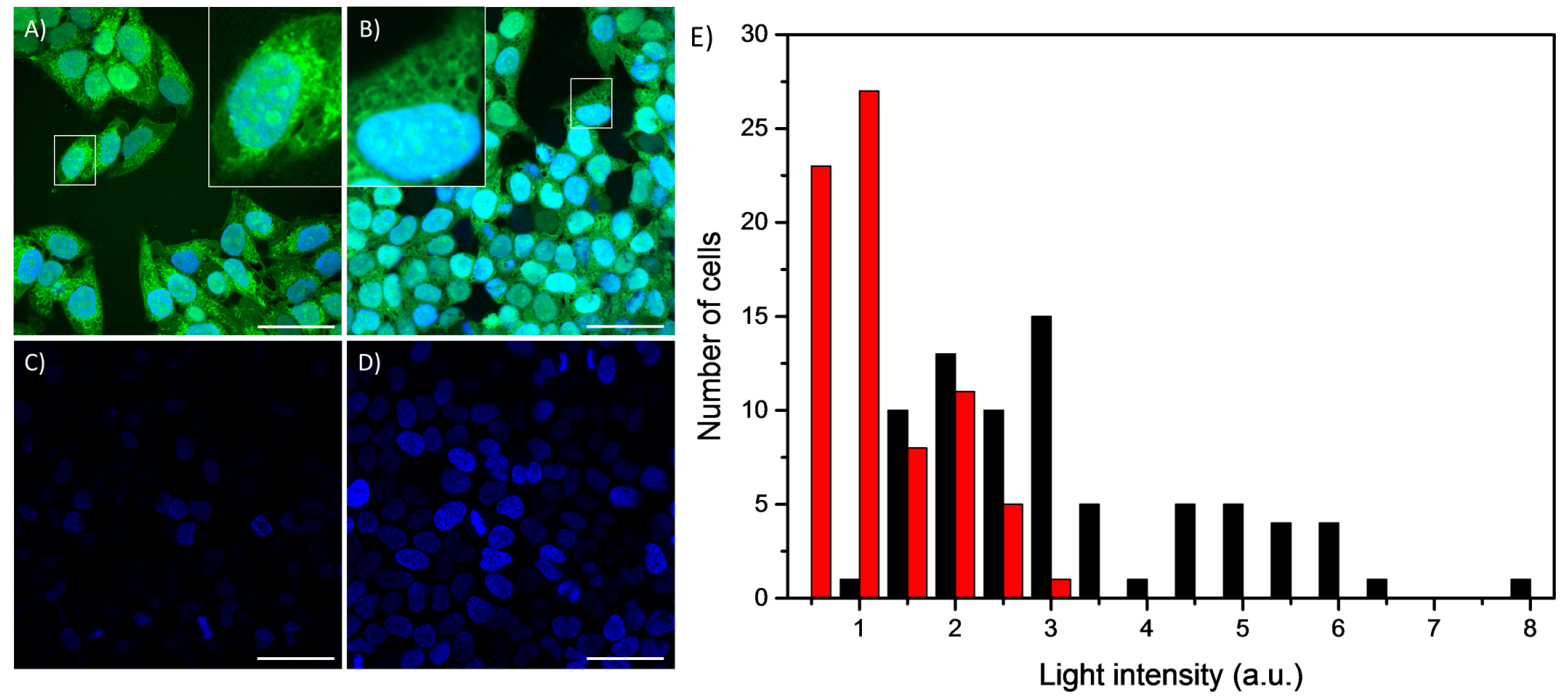

Figure S12. Confocal fluorescence microscopy images of A) fiber formation at fixed HeLa cells, B) control experiment showing only homogeneous background fluororescence, C) DAPI fluorescence when DAPI was added after gelation and D) control experiment (adding DAPI to fixed cells without gelation. E) Histogram of the light intensity of images $\mathbf{C}$ and $\mathbf{D}$. Conditions: $\mathbf{A}$ ) overnight incubation of $2 \mathrm{mM} \mathrm{1,} 12 \mathrm{mM} 2$ and $30 \mu \mathrm{M} \mathrm{5,} \mathrm{B)} 30 \mu \mathrm{M} \mathrm{5,} \mathrm{C)} 2 \mathrm{mM} 1$ and $12 \mathrm{mM} 2$ and D) untreated. All experiments performed at room temperature in a $100 \mathrm{mM}$ phosphate buffer of $\mathrm{pH} 7.0$. Scale bars: 50 $\mu \mathrm{m}$.
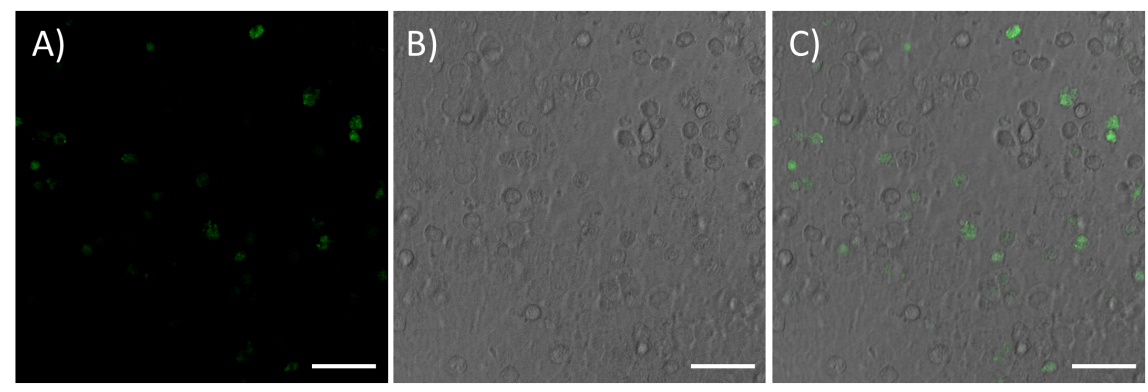

Figure S13. Control experiment where probe $4(30 \mu \mathrm{M})$ was incubated with HeLa cells overnight (37 $\left.{ }^{\circ} \mathrm{C}\right)$. Scale bars indicate $25 \mu \mathrm{m}$. 
Table S3. Cell viability experiments where the toxicity of components $\mathbf{1}$ and $\mathbf{2}$ was tested using a standard trypan blue assay. Measurements were performed in duplo and the number of cells were roughly equal for each sample. Conditions: 1) $0.5 \mathrm{mM} \mathrm{1;} \mathrm{2)} 3 \mathrm{mM} 2$ and 3) blank, all experiments performed in DMEM at $37^{\circ} \mathrm{C}, 6 \mathrm{~h}$ incubation time.

\begin{tabular}{|l|l|}
\hline Condition & Cell viability (\%) + SD \\
\hline 0.5 mM 1 & $92 \pm 1.4$ \\
\hline 3 mM 2 & $91 \pm 1.4$ \\
\hline blank & $92 \pm 3.5$ \\
\hline
\end{tabular}

\section{References}

(1) Boekhoven, J.; Poolman, J. M.; Maity, C.; Li, F.; van der Mee, L.; Minkenberg, C. B.; Mendes, E.; van Esch, J. H.; Eelkema, R. Nat. Chem. 2013, 5, 433.

(2) Crisalli, P.; Kool, E. T. J. Org. Chem. 2013, 78, 1184.

(3) Himeno, H.; Shimokawa, N.; Komura, S.; Andelman, D.; Hamada, T.; Takagi, M. Soft Matter 2014, 10, 7959. 